\title{
The National Leprosy Control Programme of Zimbabwe a data analysis, 1983-1992
}

\author{
BARRY WITTENHORST*†, MONIKA L. VREE*†, \\ PETER B. G. TEN HAM* \& JOHAN P. VELEMA $₫ \S$ \\ * Ministry of Health and Child Welfare, Harare, Zimbabwe \\ $\dagger$ Nijmegen Institute for International Health \\ $\ddagger$ Department of Public Health, Erasmus University Rotterdam, \\ P.O. Box 1738, 3000 DR Rotterdam, Netherlands
}

\section{Accepted for publication 1 December 1997}

\begin{abstract}
Summary Prevalence and detection rates of leprosy in Zimbabwe as well as patient characteristics were reported by the National Leprosy Control Programme over the 10-year period 1983-1992. The control programme made a new start in 1983 when multidrug therapy was introduced. Prevalence per 10,000 population declined steeply from 3.78 in 1983 to 0.52 in 1987. Prevalence continued to decline to 0.22 in 1992 and was highest in the north-eastern provinces. After an initial increase, the detection rate per 10,000 had declined from 0.19 in 1985 to 0.08 in 1992 . The proportion of ref ugees among new cases had gradually increased since 1988 and amounted to one third in 1991 and 1992.

An analysis of records of 802 cases who were newly detected from 1983 to 1992 showed that $51 \%$ were of the multibacillary (MB) type, 33\% had visible disabilities at detection, $5 \%$ were under 15 years of age while the average delay time was 2.6 years. Patients with disabilities reported a longer delay time, were more often men and had more often the MB type of leprosy.

The data suggest that transmission of leprosy is low but that cases are not diagnosed early enough to prevent transmission altogether.
\end{abstract}

\section{Introduction}

Between 1955 and 1964, several thousands of leprosy patients were contained in two large leprosaria in Zimbabwe, and given dapsone monotherapy. The leprosaria were closed in 1964 and the first ambulatory treatment programme was set up. Over 6000 patients were registered between 1964 and 1975. The programme almost fully collapsed during the years of struggle for independence between 1975 and 1980.

A new National Leprosy Programme was implemented in Zimbabwe at the end of $1983^{1,2}$ with assistance of the Associazione Italiana Amici di Raoul Follereau. The

$\S$ Corresponding author. 
purpose of the programme was to detect patients in an early stage of the disease and treat them with multidrug therapy (MDT) in order to provide cure, interrupt transmission and prevent leprosy-related disabilities.

In May 1991, the World Health Assembly adopted a resolution (WHA44.9) ${ }^{3}$ to eliminate leprosy as a public health problem by the year 2000 , defining elimination as the reduction of prevalence below 1 case per 10,000 population. This goal has been achieved in Zimbabwe since 1987, when the nationally registered prevalence rate dropped to 0.5 cases per 10,000 inhabitants. Since then, the transition from a vertical to a horizontal programme has begun. ${ }^{1}$

Patient data from the national leprosy control programme were analysed in the second half of 1993 in order to provide an overview of achievements in the 10 years since 1983 and to use this information as a basis for the planning of activities in the years to come. The present report of this analysis describes the leprosy situation in Zimbabwe as it developed during the 10 years from 1983 to 1992.

\section{Methods}

The leprosy control service was re-established in 1983. The programme was based on a nation-wide implementation of the WHO-recommended (MDT) ${ }^{4}$ regimens and on the integration of leprosy control into the general health services at the national, provincial, district and clinic level. Four specialized staff formed the national leprosy unit. Eight general health workers were given training in leprosy, both locally and at the All Africa Leprosy \& Rehabilitation Training Center (ALERT), and subsequently appointed as provincial leprosy officers (PLOs). They were charged with the implementation of MDT in the provinces, and with the in-service training of general health staff. ${ }^{1,2}$ Additionally, a total of 26 leprosy 'scouts' who had at least secondary school education and had worked in the health sector before, often as (environmental) health assistants, were trained within the leprosy programme to detect new cases and follow up on defaulters. Typically, a scout works in one district and accompanies other health workers who go to the field to run under five and/or vaccination clinics, provide supervision, inspect drinking water systems or the hygienic condition of markets, schools, restaurants etc. Wherever he goes, the scout will inquire into the occurrence of symptoms suggestive of leprosy, visit possible cases and patients currently under treatment. Scouts are employed in areas of high endemicity in the North and North-East; although they formally report to the district medical officer, it is the provinical leprosy officer who coordinates and supervises the work of the leprosy scouts within his province. Community health workers in Zimbabwe were trained to distinguish the most frequently occurring skin diseases including leprosy and will refer any suspected cases; he or she will also ref er any known leprosy patients who show signs of complications.

When a new case of leprosy was detected, the patient and those around him or her were given extensive explanation about the nature of the disease, risk of transmission, treatment etc. and all those living near the patient were inspected for signs of leprosy. Depending on the circumstances, this could lead to the performance of a survey in a school or on a farm, particularly if multiple cases were detected or if the patient was found to be infectious (smear-positive).

Registration of patients started in September 1983. Though most of the patients who 
first enrolled had previously been treated with dapsone monotherapy, they were, regardless of their clinical status, all registered for a final course of MDT, to avoid any impression of discrimination. After 1986, previously treated patients were only accepted for an additional course of MDT if they showed clinical or bacterial signs of active leprosy. Skin smears were taken when a patient entered the programme and at the last review before he was released from treatment (RFT). All skin-smears from leprosy patients in Zimbabwe were taken to the Parirenyatwa University Teaching Hospital in Harare and stained and read by one senior laboratory technician at the public health laboratory, who was provided with adequate equipment and specifically trained for this work at ALERT; ref resher courses were provided at regular intervals. Repeated skin smears were prepared if there was any doubt at all about the correct classification of a patient. A multibacillary patient (MB) was defined as any patient having a positive skinsmear result. Tuberculoid patients (TT and BT) were classified as paucibacillary (PB) while lepromatous patients (BB, BL and LL) were classified as $\mathrm{MB}$; these definitions did not change over the period of observation. MDT consisted for paucibacillary patients of $100 \mathrm{mg}$ dapsone each day for 6 months accompanied by $600 \mathrm{mg}(8 \mathrm{mg} / \mathrm{kg})$ rifampicin monthly. ${ }^{5}$ For multibacillary patients, MDT consisted of $100 \mathrm{mg}$ dapsone and $50 \mathrm{mg}$ clofazimine per day and $600 \mathrm{mg}(8 \mathrm{mg} / \mathrm{kg}$ ) rif ampicin plus $300 \mathrm{mg}$ clof azimine per month for a total duration of 24 months.

Assessment of patients, which was done every 3 months, included examination of the skin, palpation of the nerves, sensory tests, voluntary muscle tests and disability grading according to WHO-criteria. ${ }^{6}$ A patient was considered to be disabled when he had at least one disability grade II or III.

Data on prevalent and newly-detected cases of leprosy were given in the Annual Leprosy Reports, which were based on the quarterly Leprosy Reports from each of the provinces. More detailed information on leprosy patients was derived from a computerized database which was created from the original patient records, the ZIMLEP forms, a variation of the internationally known OMSLEP forms. A new ZIMLEP form was designed in 1988 because of some shortcomings in the old one. Data recorded in the years 1983 to 1987 were rearranged to be compatible with the new format. For every patient the first record, filled out when he entered the programme, was included in the database. In addition, the corresponding last record, filled out when the patient was released from treatment (RFT-record) was found for $58 \%$ of those who entered the programme. Not all patients who ever entered into the programme appeared in the computer register, due to computer problems since the start of the programme. Using the patients ZIMLEP forms the register was made as complete as possible, but so many years later a lot of ZIMLEP forms were missing. The final database contained 3605 records, of which 802 were from newly detected patients. Comparing the total of new cases of the period 1984-1992 between the database and the Annual Leprosy Reports, $77 \%$ of the new cases of the annual reports could be found in the database.

National Censuses were carried out in Zimbabwe in 1982 and 1992 and all rates are based on denominator information derived from the census reports by interpolation. Ref ugees are included both in the censuses and the registration of leprosy patients.

Age was calculated as the difference between year of birth and year of detection; delay time as the difference between (self-reported) age at onset of symptoms and age at detection in years. Proportions were compared by means of the $\chi$-squared test, 


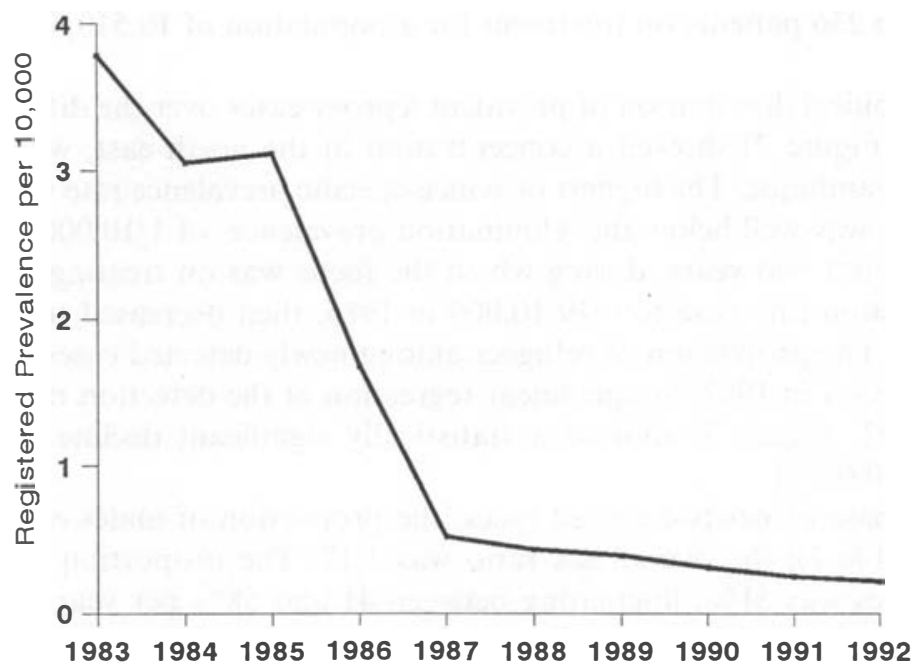

Figure 1. Annual registered prevalence of leprosy in Zimbabwe 1983-1992 per 10,000 population.

computed from a $2 \times 2$ table with the actual counts, while averages were compared with the Wilcoxon rank sum test.

\section{Results}

Prevalence of leprosy in Zimbabwe declined steeply during the years 1983 till 1987 (Figure 1 and Table 1). From 1987 onwards the prevalence rate dropped below 1 case per 10,000 population and continued to decline. At the end of 1992 the prevalence rate had

Table 1. Prevalence and incidence of leprosy in Zimbabwe, 1983-1992. Source: Annual reports, national leprosy control programme

\begin{tabular}{lcccc}
\hline Year & $\begin{array}{c}\text { Prevalent } \\
\text { cases* }\end{array}$ & $\begin{array}{c}\text { Registered } \\
\text { prevalence }\end{array}$ & $\begin{array}{c}\text { Incident } \\
\text { cases }\end{array}$ & $\begin{array}{c}\text { Detection } \\
\text { rate } \neq\end{array}$ \\
\hline 1983 & 3000 & $3 \cdot 78$ & 110 & $0 \cdot 14$ \\
1984 & 2500 & $3 \cdot 05$ & 78 & $0 \cdot 10$ \\
1985 & 2625 & $3 \cdot 11$ & 162 & $0 \cdot 19$ \\
1986 & 1451 & $1 \cdot 67$ & 146 & $0 \cdot 17$ \\
1987 & 463 & $0 \cdot 52$ & 135 & $0 \cdot 15$ \\
1988 & 403 & $0 \cdot 43$ & 106 & $0 \cdot 12$ \\
1989 & 370 & $0 \cdot 39$ & 140 & $0 \cdot 15$ \\
1990 & 311 & $0 \cdot 31$ & 102 & $0 \cdot 10$ \\
1991 & 250 & $0 \cdot 25$ & 81 & $0 \cdot 08$ \\
1992 & 236 & $0 \cdot 22$ & 86 & $0 \cdot 08$ \\
\hline
\end{tabular}

* patients under treatment on 31 december. t per 10,000 end-of-year population.

$\ddagger$ per 10,000 mid-year population. 
been reduced to 236 patients on treatment for a population of $10,510,516$ people $(0 \cdot 22)$ 10,000).

The geographical distribution of prevalent leprosy cases over the different provinces in 1990-1992 (Figure 2) showed a concentration in the north east, where Zimbabwe borders on Mozambique. The highest province-specific prevalence rate was $0 \cdot 59 / 10,000$, however, which was well below the 'elimination prevalence' of $1 / 10,000$.

After the initial two years, during which the focus was on treating already known cases, the detection rate rose to $0 \cdot 19 / 10,000$ in 1985 , then decreased to $0 \cdot 08 / 10,000$ in 1992 (Table 1). The proportion of ref ugees among newly detected cases had risen from $6 \%$ in 1988 to $35 \%$ in 1992 . Simple linear regression of the detection rates by calendar year (1985-1992, Figure 3) showed a statistically significant decline of 0.016 cases/ $10,000 /$ yr $(P<0 \cdot 0001)$.

In the database of newly-detected cases, the proportion of males exceeded $50 \%$ in most years (Table 2); the overall sex ratio was 1:17. The proportion of MB patients among new cases was $51 \%$, fluctuating between 41 and $58 \%$ per year. Patients of the MB-type occurred somewhat more frequently among men $(55 \%)$ than among women $(46 \%, P<0.05)$. The average age of newly-detected leprosy patients was generally between 40 and 45 , with an overall average of 42.7 years. Five percent of newly detected cases was under 15 years of age. The overall mean age was not statistically different between male and female or between $\mathrm{PB}$ and MB patients. The average delay time in new cases was 2.6 years; $11 \%$ of cases had experienced their first symptoms more than 5 years before the detection date while one third of these had not been detected within 10 years

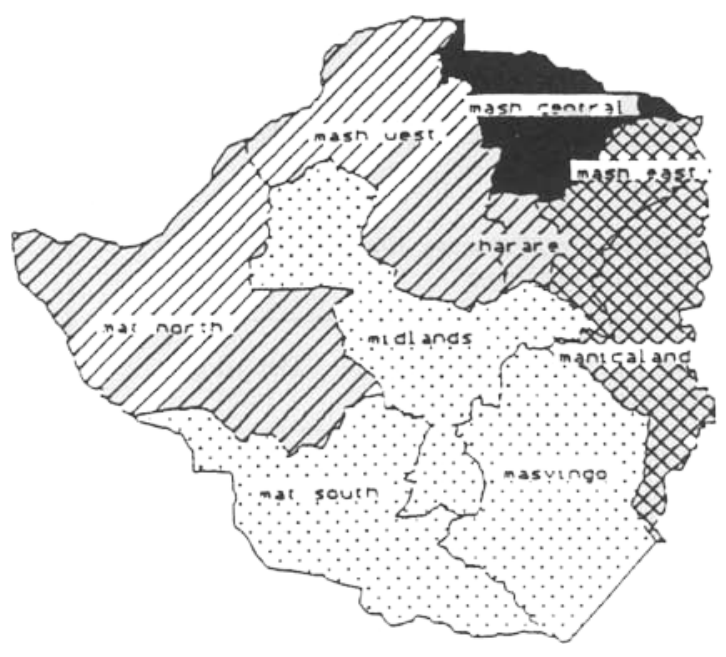

PREVALENCE / 10000

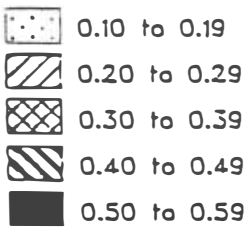

\begin{tabular}{|c|c|}
\hline Prov ince same & $\begin{array}{l}\text { Preverdes } 10.000 \\
(1990-1992)\end{array}$ \\
\hline Mancanded & 0.38 \\
\hline Ment Cenerel & 0.59 \\
\hline Math Em & 0.32 \\
\hline Mant Wore & 0.23 \\
\hline Merviepo & 0.12 \\
\hline Menth North & 0.21 \\
\hline 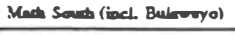 & 0.16 \\
\hline Madilande & 0.14 \\
\hline Harese & 0.22 \\
\hline Nanioned & 0.26 \\
\hline
\end{tabular}

Figure 2. Prevalence of leprosy in Zimbabwe by province (1990-1992). 


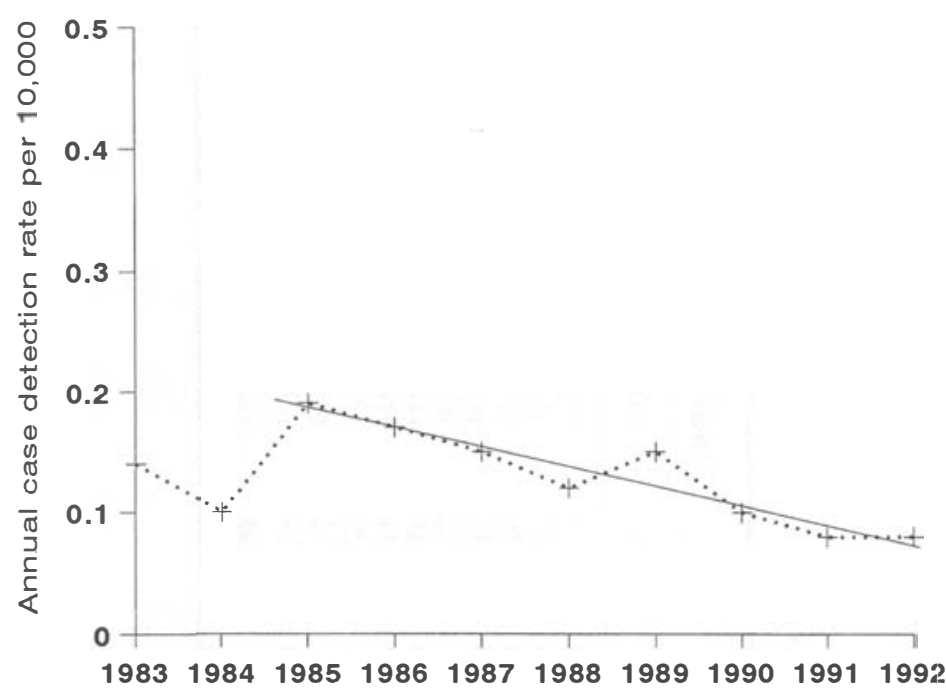

Figure 3. Annual detection of leprosy cases in Zimbabwe 1983-1992 and the simple linear regression line through the points for 1985-1992.

of onset of symptoms. Delay times exceeded 5 years in $16 \%$ of men versus $8 \%$ in women $(P<0.002)$.

The proportion of new patients with at least one grade II or III disability, calculated over the period 1983-1992, was 33\%, i.e. one out of three. A comparison of patients with and without disabilities is presented in Table 3. Patients with disabilities reported a longer delay time, were more often men, were older and had more often multibacillary leprosy. Stratification by delay time showed that a higher disability rate among men was particularly clear among patients with a delay time of 1 to 5 years (data not shown).

Information on treatment assigned at entry into the programme was missing for $19 \%$ of newly-detected cases in the years $1983-1987$ and for $8 \%$ in the years $1988-1992$. Only 14 out of 691 cases $(2 \%)$ were recorded as receiving another treatment than MDT and this proportion hardly varied from year to year. Fifteen out of 353 patients who were registered as being of the $\mathrm{MB}$-type received (at least on paper) the treatment regimen for PB patients. Twenty-seven PB-patients received the regimen for MB-patients, 21 of whom had been classified as borderline-tuberculoid.

Information on duration of treatment was available for 366 out of 802 cases $(46 \%)$. Of the 197 patients on the PB-regimen, 38 were released from treatment within 180 days and another 111 within 360 days. Of the 161 patients on an MB-regimen, 23 completed their treatment within 540 days, another 22 within 720 days, while 45 continued beyond 900 days.

Assessments of disabilities both at the beginning and completion of treatment were available for 265 out of 802 newly-detected cases (33\%). Twenty-four patients out of 180 (PB: 13/103, MB: 11/77) had developed grade II or III disabilities while under treatment; 15 out of 81 patients who had disabilities at entry had regressed. 
Table 2. Characteristics of new leprosy patients in Zimbabwe 1983-1992. Source: patient records as described in text.

.

\begin{tabular}{|c|c|c|c|c|c|c|c|c|c|c|c|c|c|c|}
\hline \multirow[b]{2}{*}{ Year } & \multirow{2}{*}{$\begin{array}{l}\text { Number of } \\
\text { new cases }\end{array}$} & \multicolumn{2}{|c|}{ Average age } & \multicolumn{3}{|c|}{$\%$ Men } & \multicolumn{3}{|c|}{ Multibacillary } & \multicolumn{3}{|c|}{ Disabled } & \multicolumn{2}{|c|}{ Delay time } \\
\hline & & $(\mathrm{m})$ & (yrs) & \# & (m) & $\%$ & \# & (m) & $\%$ & \# & $(\mathrm{m})$ & $\%$ & (m) & (yrs) \\
\hline 1983 & 8 & (0) & $40 \cdot 4$ & 8 & (0) & 100 & 4 & (0) & 50 & 1 & (1) & 14 & (0) & 3.6 \\
\hline 1984 & 88 & (0) & $42 \cdot 3$ & 42 & (0) & 48 & 38 & (1) & 44 & 22 & (8) & 28 & (1) & $2 \cdot 4$ \\
\hline 1985 & 116 & (1) & $43 \cdot 7$ & 57 & (2) & 50 & 66 & (3) & 58 & 35 & (6) & 32 & (2) & $2 \cdot 5$ \\
\hline 1986 & 94 & (2) & $45 \cdot 0$ & 52 & (3) & 57 & 45 & (2) & 49 & 33 & (4) & 37 & (7) & $3 \cdot 8$ \\
\hline 1987 & 96 & (3) & $43 \cdot 1$ & 50 & (1) & 53 & 49 & (0) & 51 & 12 & (6) & 13 & (3) & $2 \cdot 7$ \\
\hline 1988 & 87 & (2) & $40 \cdot 0$ & 48 & (2) & 56 & 41 & (3) & 49 & 35 & (4) & 42 & (17) & $2 \cdot 4$ \\
\hline 1989 & 118 & (0) & $45 \cdot 0$ & 66 & (0) & 56 & 65 & (3) & 57 & 55 & (7) & 50 & (24) & $2 \cdot 1$ \\
\hline 1990 & 77 & (1) & $45 \cdot 3$ & 44 & (0) & 57 & 34 & (1) & 45 & 25 & (7) & 36 & (12) & $3 \cdot 2$ \\
\hline 1991 & 64 & (3) & $34 \cdot 1$ & 37 & (0) & 58 & 26 & (1) & 41 & 12 & (0) & 19 & (4) & 1.9 \\
\hline 1992 & 54 & (5) & $41 \cdot 4$ & 22 & (2) & 42 & 31 & (1) & 59 & 19 & (2) & 37 & (12) & $2 \cdot 0$ \\
\hline Total & 802 & (17) & $42 \cdot 7$ & 426 & (10) & 54 & 399 & (15) & 51 & 249 & (44) & 33 & (82) & $2 \cdot 6$ \\
\hline
\end{tabular}

(m): number of patients for which information is missing. 
Table 3. Comparison of patients with and without grade II or III disabilities at the time of detection

\begin{tabular}{|c|c|c|c|c|c|}
\hline & \multicolumn{4}{|c|}{ Disabilities } & \\
\hline & \multicolumn{2}{|c|}{ yes } & \multicolumn{2}{|c|}{ no } & \\
\hline & \# & $(\%)$ & \# & $(\%)$ & \\
\hline $\begin{array}{l}\text { Type of leprosy } \\
\text { MB } \\
\text { PB }\end{array}$ & $\begin{array}{l}138 \\
107\end{array}$ & $\begin{array}{l}(56) \\
(44)\end{array}$ & $\begin{array}{l}239 \\
261\end{array}$ & $\begin{array}{l}(48) \\
(52)\end{array}$ & $P<0.05$ \\
\hline $\begin{array}{l}\text { Sex } \\
\text { Females } \\
\text { Males }\end{array}$ & $\begin{array}{r}92 \\
155\end{array}$ & $\begin{array}{l}(37) \\
(63)\end{array}$ & $\begin{array}{l}258 \\
241\end{array}$ & $\begin{array}{l}(52) \\
(48)\end{array}$ & $P<0.001$ \\
\hline $\begin{array}{l}\text { Delay time* } \\
0 \\
1-5 \\
6-10 \\
>10\end{array}$ & $\begin{array}{r}29 \\
149 \\
32 \\
15\end{array}$ & $\begin{array}{r}(13) \\
(66) \\
(14) \\
(7)\end{array}$ & $\begin{array}{r}119 \\
301 \\
28 \\
15\end{array}$ & $\begin{array}{l}(26) \\
(65) \\
(6) \\
(3)\end{array}$ & $P<0.001$ \\
\hline mean \pm s.e. & \multicolumn{2}{|c|}{$3.5 \pm 0.27$} & \multicolumn{2}{|c|}{$2.3 \pm 0.21$} & $P<0.001$ \\
\hline $\begin{array}{l}\text { Age* }^{*} \\
<15 \\
15-24 \\
25-34 \\
35-44 \\
45-54 \\
55-64 \\
\geq 65\end{array}$ & $\begin{array}{r}6 \\
17 \\
26 \\
48 \\
71 \\
41 \\
35\end{array}$ & $\begin{array}{l}(2) \\
(7) \\
(11) \\
(20) \\
(29) \\
(17) \\
(14)\end{array}$ & $\begin{array}{r}24 \\
69 \\
85 \\
95 \\
109 \\
72 \\
43\end{array}$ & $\begin{array}{l}(5) \\
(14) \\
(17) \\
(19) \\
(22) \\
(14) \\
(9)\end{array}$ & $P<0.001$ \\
\hline mean \pm s.e. & \multicolumn{2}{|c|}{$47.1 \pm 1.00$} & \multicolumn{2}{|c|}{$40.8 \pm 0.75$} & $P<0.001$ \\
\hline
\end{tabular}

\footnotetext{
* Age and delay time in years.
}

\section{Discussion}

\section{PREVALENCE AND INCIDENCE}

The dramatic drop in prevalence of leprosy during the first 5 years of activities is not surprising, as MDT was now abundantly available and intake criteria were generous. ${ }^{7}$ The observation that prevalence has continued to decline after 1987 is more encouraging. The low current prevalence levels (257 prevalent cases in 1994, a rate of 0.24 / $10,000^{8}$ ) suggest that transmission of leprosy is low in Zimbabwe. This is confirmed by the observation that incidence has decreased from 1985 to 1992 with 1989 as the only exception. This exception is probably due to the influx of refugees from neighbouring Mozambique around that time. Between 10,000 and 20,000 refugees from Mozambique had been placed in camps in Zimbabwe by the end of 1984; this number suddenly rose to 130,000 in 1989. The prevalence of leprosy in Mozambique was 8.86 per 10,000 in $1994^{8}$ while the prevalence in Zambia was 2.26. In southern-adjacent South Africa, the prevalence was 0.09 per 10,000 population, while Botswana did not report any cases at all in $1994 .^{8}$

BCG coverage among 1 year olds in Zimbabwe rose from $64 \%$ in 1981 to $86 \%$ in 1987 and has stabilized at the level of $80 \%$ since $^{9}$. This may have contributed to the present low transmission of leprosy in Zimbabwe, ${ }^{10}$ although it should be remembered 
that an effect of BCG vaccination on adult leprosy incidence takes at least 15 years to become observable. The observed low detection rate among children is more likely to be influenced by the favourable BCG-coverage.

The observed decreasing incidence of leprosy is only valid if the case-finding activities were maintained at the same level. We were not able to compare registered cases to the total number of cases of leprosy in the country. ${ }^{11}$ Unfortunately, the cost of detecting a case of leprosy increases as incidence decreases. In addition, fewer resources are available for this work as leprosy becomes less and less of a public health problem. ${ }^{12}$ A proportion of $37 \%$ of new cases with disabilities grade II or III in 1992 (Table 2) is high compared to other countries in Africa ${ }^{13}$ and suggests that cases are not diagnosed as early as would be desirable if transmission were to be blocked completely. ${ }^{2,11}$ The presence of disabilities was clearly related to a long delay time (Table 3). However, there does not seem to be a systematic rise or fall of the disability rate over time. The association of the disability rate with age, sex and MB-type is well known. ${ }^{14}$

\section{DATA QUALITY}

Although 110 incident cases were detected in 1983 (Table 1), the records of only eight of these cases were available for analysis (Table 2); for 1984, the records of 88 cases were available while 78 were counted in the annual report. Clearly, the registration of new cases was incomplete in that initial period during which all efforts were focused on getting large numbers of known patients started on MDT.

Errors in recording of information and in data processing may have occurred and this could partly explain why some patients seem to have received the wrong treatment regimen. Information on duration of treatment and progression or regression of disabilities during treatment may have been affected by errors in linking information recorded at entry into the programme and at discharge. All information in Tables 2 and 3 , however, was derived from the entry record of each patient and has not been affected by problems of record-linkage.

\section{SIGNS OF LATTER DAYS FOR LEPROSY}

The question whether special epidemiological characteristics can be described in situations where leprosy is dying out has been raised by Irgens. ${ }^{15}$ He suggested that new cases will be older at detection in such situations and more of ten of the lepromatous type. The present data do not show a gradual increase of age at detection or of the type-index over time (Table 2). However, the proportion of MB-patients in Zimbabwe is high compared to other African countries such as Burkina Faso $(4 \%)$, Tanzania $(18 \%)^{16}$ or Malawi $(20 \%),{ }^{12}$ data from northern Malawi ${ }^{17,18}$ yield an MB-proportion of only $6 \%$. A possible explanation for this high percentage could be that the few cases that occur in areas where leprosy is dying out generally have a weaker resistance resulting in a predominance of multibacillary leprosy (Dr J. A. Warndorff, personal communication, $c f .{ }^{17}$ ). A study in the Shoa administrative region in Ethiopia in the years 1984-1988 showed an MB-proportion of 43\% not accompanied by a shift to older age-groups. ${ }^{19}$ 


\section{INTEGRATION WITH OTHER HEALTH SERVICES}

The national leprosy unit was reduced in 1991 from 4 staff to 2 part-time staff who were at the same time involved in tuberculosis control. This adjustment was a consequence of the reduction of the leprosy prevalence coinciding with a rising incidence of tuberculosis. Since donors made less money available for leprosy control in low-prevalence countries, the continuation of leprosy control in Zimbabwe was dependent on a further integration of tuberculosis and leprosy control activities. From 1992 onwards, staff from both programmes were integrated on the provincial and district levels as well. A similar attempt at integration was reported from India. ${ }^{20}$

A further step towards integration was made in the area of rehabilitation of leprosy patients with disabilities. The existing leprosy rehabilitation schemes were independent of the nationwide community-based rehabilitation programme which dealt with nonleprosy-related disabilities. A project was therefore started in 1991 with assistance of the Leprosy Mission International to train rehabilitation staff at different levels of the health system on the treatment and rehabilitation of leprosy patients. ${ }^{2}$ By reviewing together with local leprosy staff the leprosy cases actually under treatment at the time, discussions on referral of leprosy patients to the community-based rehabilitation programme can take place. Full integration of leprosy patients in the community-based rehabilitation programme is expected in approximately 3 years.

\section{Acknowledgments}

The authors wish to thank the Associazione Italiana Amici di Raoul Follereau for providing shelter and transport and IBM Netherlands for lending a laptop computer during the data collection phase, the Ministry of Health \& Child Welfare for permission to publish and Mr A. Meima for generously supplying literature and helpful comments.

\section{References}

${ }^{1}$ Warndorff DK \& Warndorff JA. Leprosy control in Zimbabwe: from a vertical to a horizontal programme. Lepr Rev, 1990; 61: 183-187.

2 Mudarokwa LC, ten Ha m PBG. Ten years of multidrug therapy in Zimbabwe (abstract). Int J Lep, 1993; 61: 44A.

${ }^{3}$ Feenstra P. Needs and prospects for epidemiological tools in leprosy control. Lepr Rev, 1992; 63: Supplement, 3s-10s.

${ }^{4}$ WHO Study Group. Chemotherapy of leprosy for control programmes. Technical Report Series No. 675, WHO, Geneva, 1982.

5 Essential drugs list for Zimbabwe 1994-including guidelines for treatment of medical conditions common in Zimbabwe. Ministry of Health and Child Welfare, Harare, 1993.

6 WHO Expert Committee on Leprosy. Technical Report Series No. 189, WHO, Geneva, 1960.

7 Noordeen SK, Lopez Bravo L, Sundaresan TK. Estimated number of leprosy cases in the world. Lepr Rev, 1992; 63: 282-287.

8 WHO. Weekly Epidemiological Record, 30 June 1995; 70: 185-188.

9 UNICEF. The state of the world's children. editions for the years 1987-1995. Oxford University Press.

10 Karonga Prevention Trial Group. Randomized controlled trial of single BCG, repeated BCG, or combined BCG and killed Mycobacterium leprae vaccine for prevention of leprosy and tuberculosis in Malawi. Lancet, 348: 17-24, 1996.

11 Thet Htoon M. Indicators for use in leprosy control programmes. Le pr Rev, 1992; 63: supplement, 73s-76s. 
12 Boerrigter G, Pönnighaus JM. Does the introduction of WHO-MDT influence trends in the incidence of leprosy? The Malawian experience. Lepr Rev, 1993; 64: 227-235.

13 WHO. Weekly Epidemiological Record, 22 September 1995; 70: 269-275.

${ }^{14}$ Smith WCS. The epidemiology of disability in leprosy including risk factors. Lepr Rev, 1992; 63: supplement $23 \mathrm{~s}-30 \mathrm{~s}$.

15 Irgens LM. Secular trends in leprosy: increase in age at onset associated with declining rates and long incubation periods. Int J Leprosy, 1985; 53: 610-617.

16 Noordeen SK. The epidemiology of leprosy. Medicine in the tropics. Leprosy. RC. Hastings. Churchill Livingstone, New York, 1985.

17 Pönnighaus JM, Fine PEM, Sterne JAC, Bliss L, Wilson R J, Malema SS, Kileta S. Incidence rates of leprosy in Karonga district, northern Malawi: patterns by age, sex, BCG-status and classification. Int J Lepr, 1994; 62: $10-23$.

18 McDougall AC, Pönnighaus JM, Fine PEM. Histopathological examination of skin biopsies from an epidemiological study of leprosy in northern Malawi. Int J Lepr, 1987; 55: 88-98.

19 Berhe D, Haimanot RT, Tedla T, Taddesse T. Epidemiological pattern of leprosy in Ethiopia: a review of the control programmes. Lepr Rev 1990; 61: 258-266.

${ }^{20}$ Kharkar RD, Nagaraj K, Mane GS. Impact of multi-drug therapy on the field workers in leprosy and their future prospects (abstract). Int $J$ Lep, 1993; 61: 57A. 